\title{
Aplikasi WAP dengan WML, PHP \& MySQL dalam Sistem Informasi Akademik
}

\author{
R. Deasy Mandasari ${ }^{1}$ \\ ${ }^{1}$ Program Studi Teknik Elektro, Fakultas Teknik dan Informatika, Universitas Bina Sarana Informatika \\ J1. Kramat Raya No.98, Jakarta Pusat, DKI Jakarta 10450, Indonesia \\ e-mail: ${ }^{1}$ deasy.rde@bsi.ac.id
}

Artikel Info : Diterima : 26-12-2020| Direvisi : 08-01-2021 | Disetujui : 13-01-2021

\begin{abstract}
Abstrak - Sistem Informasi Akademik adalah suatu sistem yang dibuat untuk mendukung proses pengelolaan data informasi akademik baik itu info untuk Dosen maupun Mahasiswa di lingkungan perguruan tinggi. Sistem ini berfungsi sebagai fasilitator dalam penyediaan informasi akademik yang dapat diakses secara online sehingga dapat diakses dimana saja dan kapan saja karena syaratnya hanya telepon yang terhubung dengan media internet. Oleh karena itu, dibuatlah suatu sistem tampilan aplikasi smartphone sebagai pusat informasi perguruan tinggi yang dapat terintegrasi dan menjawab permasalahan yang terjadi mengenai pengelolaan data akademik yang belum tersusun dengan baik yaitu mengenai data Dosen maupun data Mahasiswa. Dengan menggunakan teknologi Wireless Application Protocol (WAP) menjadikan smartphone sebagai media untuk mengakses segala informasi mengenai data akademik perguruan tinggi secara efisien. Berdasarkan latar belakang tersebut, maka permasalahan yang diambil adalah dengan cara membuat suatu sistem informasi akademik berbasis pemrograman WML, PHP melalui sistem database MYSQL. Tujuannya adalah untuk mengetahui bagaimana sistem informasi akademik berbasis WAP dengan WML, PHP, dan MySQL. Metode penelitian yang dilakukan ditempuh dengan metode observasi, literatur, dan pengembangan sistem. Hasil penelitian ini adalah sistem informasi akademik yang dapat diakses melalui website dan WAP melalui smartphone dengan pemrograman WML, PHP, dan MYSQL sebagai databasenya. Kedepannya aplikasi ini akan selalu dikembangkan mengikuti perkembangan informasi akademik di perguruan tinggi khususnya juga untuk mendukung program Kampus Merdeka.
\end{abstract}

Kata Kunci : MySQL, PHP, Sistem Informasi Akademik, Wireless Application Protocol (WAP), WML.

Abstracts - Academic Information System is a system designed to support the process of data management of academic information, be it information for lecturers or students in higher education. This system functions as a facilitator in providing academic information that can be accessed online so that it can be accessed anywhere and anytime because the condition is only a telephone connected to the internet media. Therefore, a smartphone application display system was created as a university information center that could be integrated and answered problems that occurred regarding the management of academic data that had not been structured properly, namely regarding Lecturer and Student data. By using the Wireless Application Protocol (WAP) technology, smartphones are used as a medium to efficiently access all information regarding higher education academic data. Based on this background, the problem to be taken is to create an academic information system based on WML and PHP programming through the MYSQL database system. The aim is to find out how the WAP-based academic information system with WML, PHP, and MySQL. The research method used is the method of observation, literature, and system development. The result of this research is an academic information system that can be accessed via a website and WAP via a smartphone with WML, PHP, and MYSQL programming as the database. In the future, this application will always be developed following the development of academic information in higher education, especially to support the Independent Campus program.

Keywords : Academic Information System, MySQL, PHP, Wireless Application Protocol (WAP), WML. 


\section{PENDAHULUAN}

Berdasarkan Penelitian terdahulu dalam Buku berjudul Panduan Sistem Informasi Akademik Sekolah Berbasis Web (Ahmar, 2019) yang membahas mengenai Sistem Informasi Akademik Sekolah yang merupakan suatu aplikasi yang membantu sekolah untuk mengelola data-data mengenai data akademik.

Pada penelitian ini WML, PHP dan MYSQL diaplikasikan untuk menciptakan suatu sistem informasi akademik yang tersedia pada smartphone sehingga memudahkan dalam pencarian informasi akademik secara menyeluruh hanya dengan media handphone serta dapat mengatasi kelemahan pada sistem informasi akademik yang menggunakan website dan media SMS online untuk memberi informasi yang lebih fresh dan up to date.

Berkembangnya pendidikan di Indonesia termasuk program Pemerintah membuat perguruan tinggi menjadi Kampus Merdeka menuntut penyesuaian sumber daya akademik yang berkualitas, termasuk aplikasi informasi kampus maupun Sumber Daya Manusia (SDM)-nya. Penggunaan teknologi yang praktis dan efisien demi mendukung program ini wajib terus dibuat dan dikembangkan agar lebih variatif dan berdaya guna.

\section{Sistem Basis Data}

Basis Data adalah kumpulan dari suatu susunan data dalam sebuah organisasi yang diatur dan disimpan secara rapi dengan menggunakan komputer sebagai media, sehingga dapat menyajikan informasi yang bermanfaat untuk penggunanya (Atikah \& Sukadi, 2013).

Sedangkan sistem basis data adalah suatu sistem yang dikelola dari beberapa data yang sudah tersimpan dalam komputer dan telah disusun dengan rapi dalam sebuah folder/drive sehingga dapat diambil dan digunakan oleh suatu perusahaan untuk informasi selanjutnya dalam pengambilan sebuah keputusan (Triansah dkk., 2016).

\section{Relational Database Management System (RDBMS)}

Proses pengelolaan data yang telah dikumpulkan dalam sebuah sistem disebut DBMS (Abdulghani \& Solehudin, 2018).

$D B M S$ adalah hal utama dalam mengelola data sebagai sebuah informasi. Untuk membangun sistem pengelolaan data informasi tersebut, dibutuhkan perangkat lunak (software) yang sering digunakan untuk DBMS (Data Base Management System) dkk., 2015).

Hal-hal yang dilakukan oleh software DBMS ini adalah membuat kumpulan data, menyimpan data, menampilkan data, mengupdate data, menghasilkan laporan sesuai dengan data yang telah disimpan, dan mengamankan data tersebut agar tidak disalahgunakan (Setyawan, 2013).

\section{Wireless Application Protocol}

WAP merupakan sebuah aplikasi yang menyajikan informasi apapun menggunakan browser pada smartphone dengan media internet (Pt dkk., 2011). WAP merupakan aplikasi XML versi 1.0. WAP Server dibuat menggunakan Apache Web Server sebagai aplikasinya, sedangkan WAP dibuat menggunakan pemrograman WML (Priyanto, 2013).

\section{a. Wireless Markup Language (WML)}

WML merupakan bahasa pemrograman untuk menampilkan suatu informasi dari halaman WAP browser. WML merupakan bagian dari bahasa pemrograman $H T M L$, tetapi didasarkan pada bahasa $X M L$. Halaman WML disebut dengan deck, yaitu kumpulan dari card (Marhaeni, 2017).

b. Pemrograman PHP

WampServer adalah software installer PHP secara instant yang berjalan pada lingkungan Windows, PHP, Apache Web Server, dan MySQL akan ter-install otomatis jika proses install WampServer telah selesai. PHP dan HTML sudah terintegrasi dan dijalankan pada server side artinya setiap bahasa yang dimasukkan akan dijalankan oleh server dan ditampilkan oleh browser. Fungsi yang selalu akan ditampilkan dalam bahasa pemrograman ini adalah echo yang digunakan untuk menampilkan suatu data ke dalam browser (Dhanta dikutip dari Sanjaya, 2015).

c. Konfigurasi Pemrograman $P H P$ dan $W M L$ dalam Database $M y S Q L$

Untuk dapat menampilkan halaman yang dibuat melalui $P H P$ dan menampilkan database yang sedang bekerja pada $P H P$, dikolaborasikan struktur listing program $P H P$ dengan $W M L$. Dengan menggunakan $P H P$ dapat membantu sistem database MySQL sehingga jika diaplikasikan dengan $W M L$, akses halaman pada browser yang ditampilkan akan bersifat responsif baik itu tampilan melalui website maupun smartphone (Wijaya dkk., 2010).

$<$ ?php

header('Content-type:text/vnd.wap.wml'); 


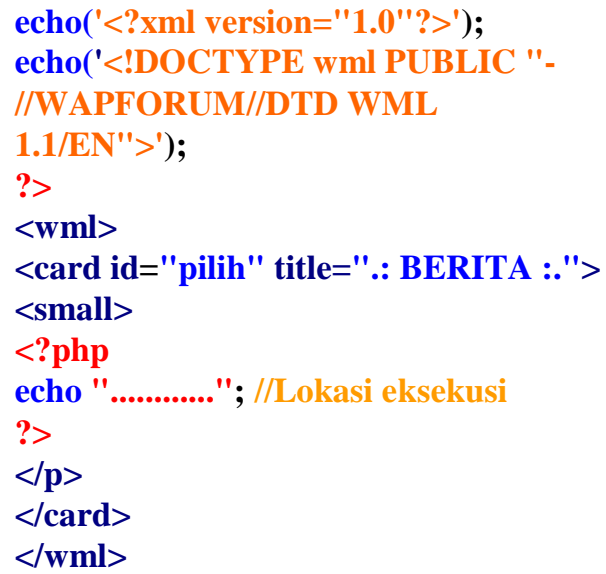

Perbedaan warna diatas menunjukkan bahasa dari masing-masing script code untuk menempatkan database $M Y S Q L$ dari $P H P$ yang dijalankan.

\section{METODE PENELITIAN}

Metode yang dipakai untuk penelitian ini adalah bagaimana cara membuat sebuah aplikasi sistem informasi akademik sehingga dapat diakses melalui smartphone, dengan menggunakan platform WML, PHP dan sistem database MYSQL sebagai bahasa pemrogramannya. Fokus penelitian ini adalah pembuatan script code WML yang dikolaborasikan dengan PHP programming yang terkoneksi dengan sistem database MYSQL, dan untuk mengetahui bagaimana cara sistem untuk dapat menampilkan pada media telepon seluler.

Pada dasarnya WAP sistem informasi akademik Departemen Pendidikan Teknik Elektro Universitas Pendidikan Indonesia ini adalah aplikasi client/server yang menggunakan media internet untuk dapat berjalan dengan baik, aplikasi ini membutuhkan beberapa komponen, yaitu sebagai berikut:

1. Apache versi 2.2.11 sebuah server web.

2. MYSQL versi 5.1.36 sebuah RDBMS (Relational Database Management System) multiuser berkemampuan tinggi yang dirancang untuk bekerja pada berbagai macam platform.

3. Sebagai client, digunakan browser web Internet Explorer versi 6.0, Mozilla Firefox versi 3.5.5 dan Opera Mobile Browser versi 10.00.

4. PHP versi 5.3.0 yang merupakan bagian dari server web.

5. WampServer versi 2.0, sebagai sistem operasi server.

6. WML page design menggunakan CSS Style Sheet yang terdiri dari halaman informasi umum, sarana pendidikan, sistem informasi akademik, pendaftaran dan halaman bantuan.

a. Data Flow Diagram

Pembuatan Data Flow Diagram (DFD) dalam sistem informasi akademik dilakukan untuk mengetahui alur proses data yang dibentuk menjadi suatu diagram. $D F D$ merupakan cara untuk menampilkan suatu proses penyampaian informasi dalam sebuah sistem sehingga mengetahui peran fungsi dan tujuan antar sistem yang akan dibuat (Sanjaya, 2015). 


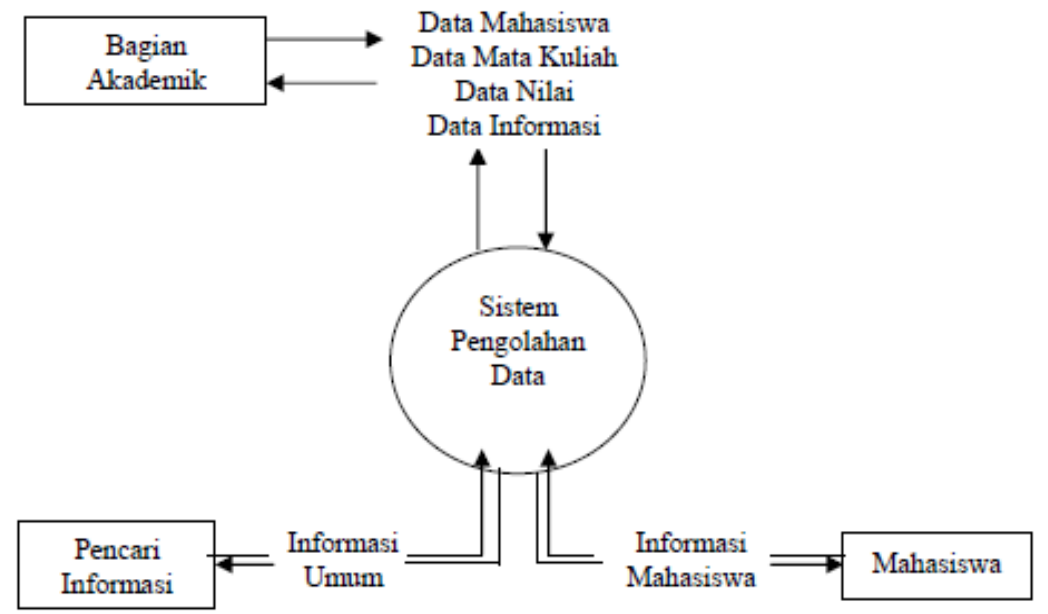

Gambar 1. Data Flow Diagram Sistem Informasi Akademik

b. State Diagram

Perencanaan perancangan sistem yang dilakukan adalah membuat aplikasi sistem menggunakan state diagram yang dibuat, seperti yang digambarkan di bawah ini:

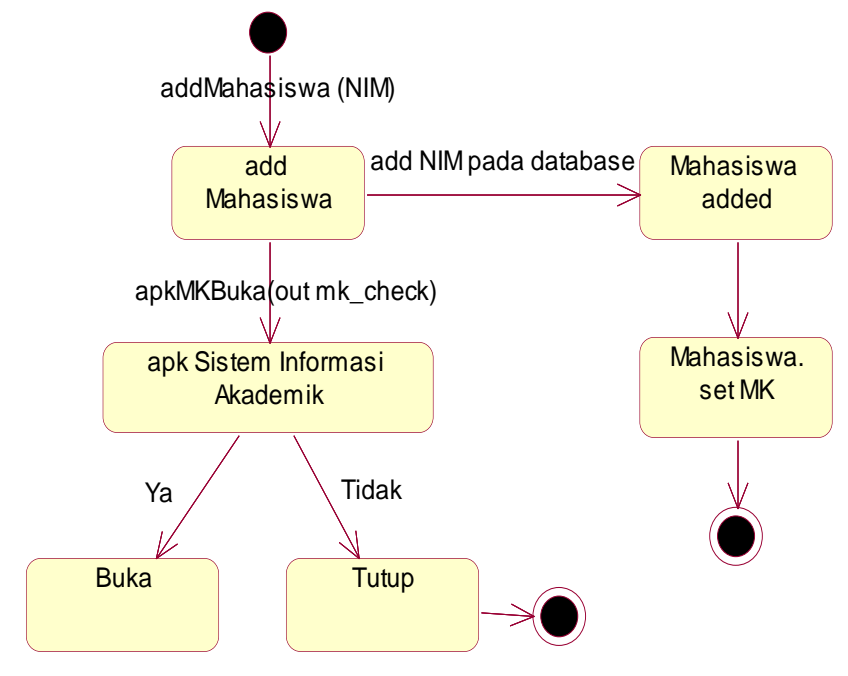

Gambar 2. Gambar State Diagram Sistem Informasi Akademik

c. Sequential Diagram

Karena sequential diagram mengacu kepada objek, maka sebelum membuat diagram ini class diagram harus sudah teridentifikasi. UML memberikan tiga stereotype untuk class yaitu boundary, control dan entity, atau lebih mudah disingkat dengan $B C E$. 


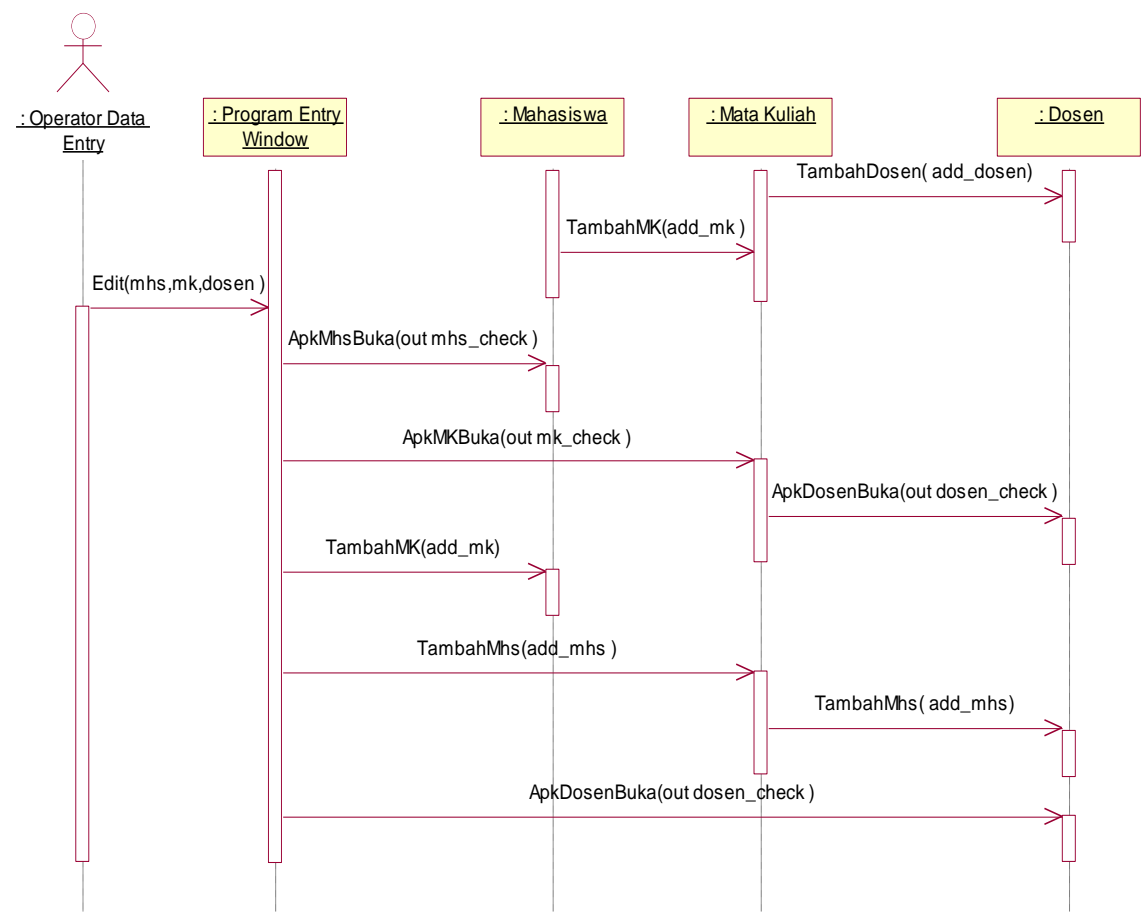

Gambar 3. Sequential Diagram Sistem Informasi Akademik

\section{HASIL DAN PEMBAHASAN}

Hasil dari penelitian ini adalah terbentuknya suatu aplikasi sistem informasi akademik WAP, WML, dan MySQL yang dapat diakses dengan menggunakan smartphone yang dapat juga ditampilkan dalam website melalui komputer dengan tampilan yang responsive.

1. Analisis Data Flow Diagram

Dari $D F D$ sistem informasi akademik basis data sistem yang terdiri dari data mahasiswa, data mata kuliah, data nilai serta data informasi dapat dijabarkan seperti gambar 4. 


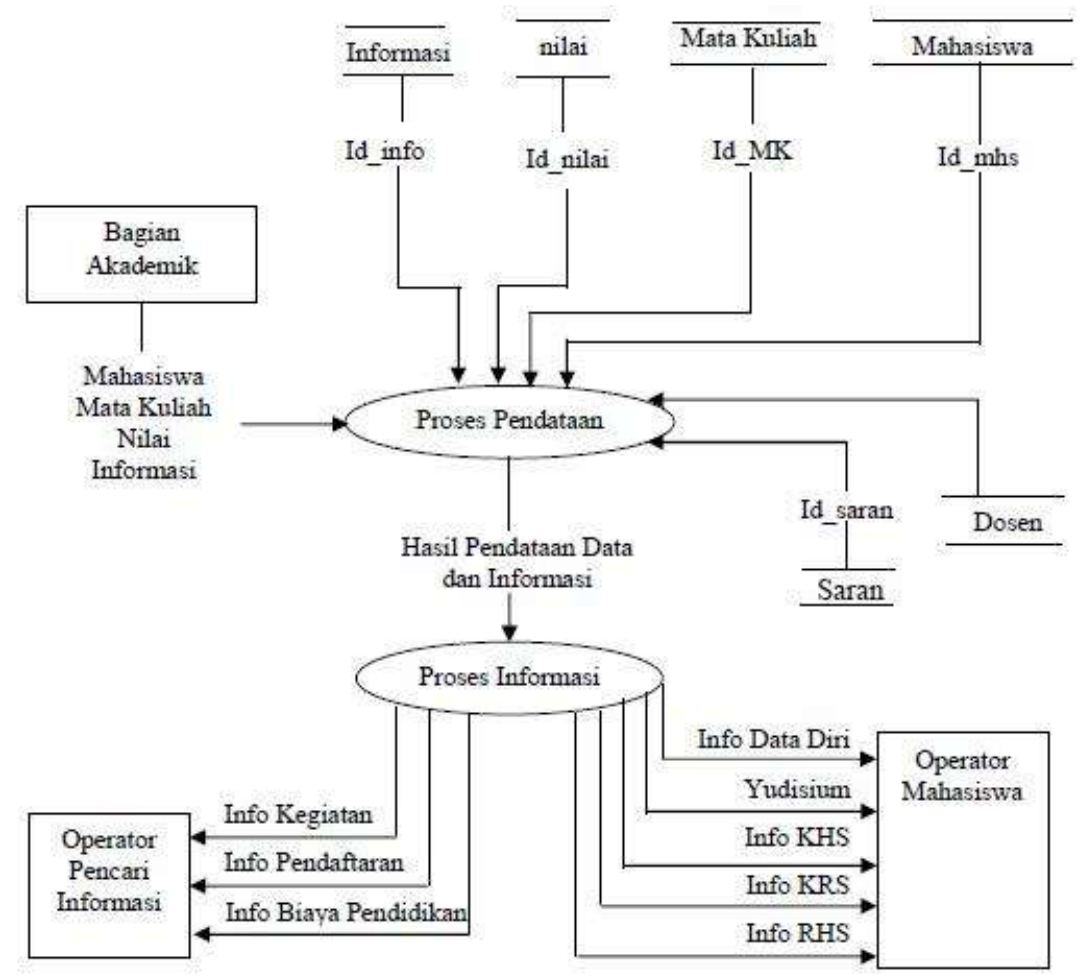

Gambar 4. DFD Level 1 Sistem Informasi Akademik

\section{Use Case Diagram}

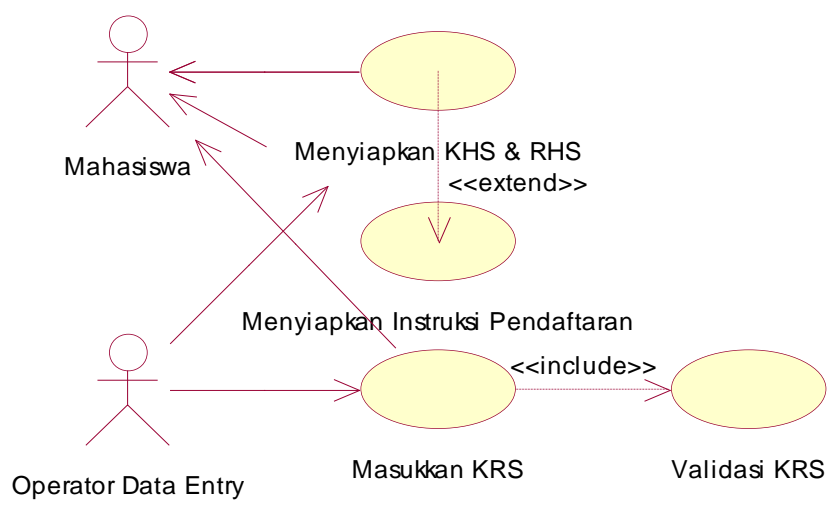

Gambar 5. Use Case Diagram Sistem Informasi Akademik

Tabel 1. Deskripsi Use Case (Mahasiswa)

\begin{tabular}{|c|c|}
\hline Use Case & Sistem Informasi Akademik \\
\hline Deskripsi Singkat & $\begin{array}{l}\text { Use case ini memungkinkan sistem untuk menampilkan informasi } \\
\text { akademik berupa tampilan halaman KRS, KHS dan RHS. }\end{array}$ \\
\hline Aktor & Mahasiswa \\
\hline Pre Condition & $\begin{array}{l}\text { Mahasiswa menggunakan form input login untuk memasuki halaman } \\
\text { web sistem informasi akademik. }\end{array}$ \\
\hline Main Flow & $\begin{array}{l}\text { Use case ini dimulai saat Mahasiswa memutuskan untuk melihat } \\
\text { informasi akademik dengan memasukkan NIM dan password ketika } \\
\text { form input login ditampilkan di layar. }\end{array}$ \\
\hline Alternative Flow & $\begin{array}{l}\text { Jika Mahasiswa menjalankan fungsi login sebelum form input login } \\
\text { semuanya terisi, sistem otomatis akan menampilkan warning } \\
\text { message (error) dan meminta kepada Mahasiswa untuk register } \\
\text { terlebih dahulu. }\end{array}$ \\
\hline
\end{tabular}


Mahasiswa bisa memilih Reset untuk mengosongkan form input sign up, sehingga sistem mengijinkan Mahasiswa untuk memasukkan informasi lagi.

Jika use case sukses dijalankan, sistem akan menampilkan informasi

Post Condition akademik berupa display KRS, KHS dan RHS sesuai data yang diinputkan user (Mahasiswa). Jika tidak status tidak berubah.

Tabel 2. Deskripsi Use Case (Operator)

\begin{tabular}{cl}
\hline Use Case & \multicolumn{1}{c}{ Sistem Informasi Akademik } \\
\hline Deskripsi Singkat & Use case ini memungkinkan sistem untuk menampilkan halaman KRS. \\
Aktor & $\begin{array}{l}\text { Operator } \\
\text { Operator menggunakan phpMyAdmin untuk membuat database tampilan } \\
\text { sistem informasi akademik. }\end{array}$ \\
Pre Condition & Use case ini dimulai saat Operator memutuskan untuk membuat database \\
informasi akademik dengan memasukkan NIM, mata kuliah dan nilai pada \\
data mahasiswa.
\end{tabular}

3. Relasi Antar Tabel

Pada setiap tabel yang berhubungan memiliki kunci primer, kunci kandidat dan kunci tamu.

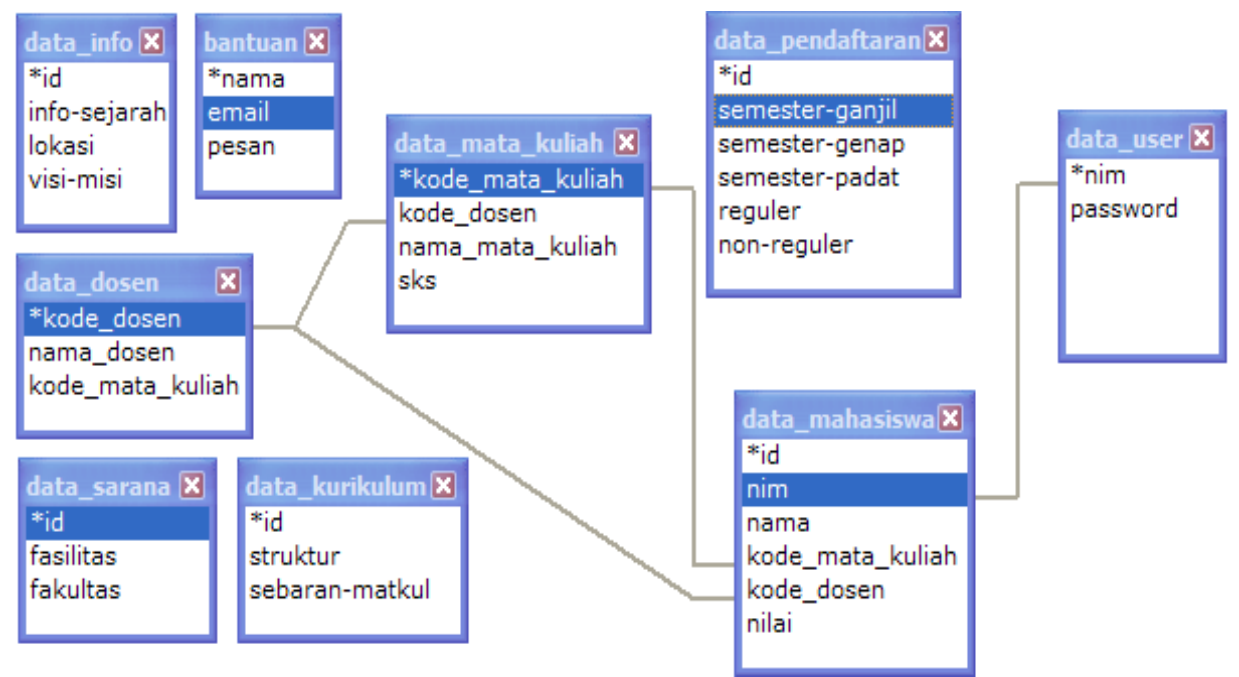

Gambar 6. Relasi Antar Tabel Sistem Informasi Akademik Berbasis WAP

4. Hasil Pengujian Program

Konfigurasi script coding WML dan PHP yang telah dibuat perlu dilakukan pengujian program. Pengujian sangat diperlukan untuk membuktikan bahwa program dapat dijalankan sesuai dengan yang diinginkan dan benar hasilnya.

Karena sifat bahasa pemrograman adalah melakukan apa yang diinginkan oleh operator dalam hal ini browser, jadi sistem komputerisasi hanya sebatas memproses dan telepon seluler hanya terbatas pada melakukan displai data.

Bila dianggap memenuhi ketentuan dalam bahasa pemrograman maka sistem akan menjalankan perintah serta mengeluarkan hasil. Untuk itu diperlukan beberapa cara terhadap pengujian yang akan dilakukan.

Tabel 3. Hasil Uji Modul

\begin{tabular}{ccc}
\hline No. & Tampilan & Keterangan \\
\hline 1. & menu_utama.php & $\begin{array}{c}\text { Sesuai dengan diagram } \\
\text { alir }\end{array}$
\end{tabular}




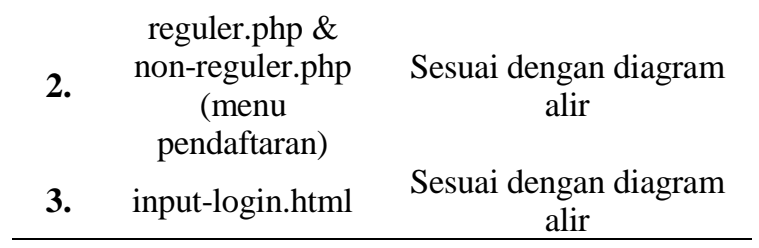

Tabel 4. Hasil Uji Pengembangan

\begin{tabular}{|c|c|c|}
\hline No. & Tampilan & Keterangan \\
\hline 1. & menu_utama.php & $\begin{array}{l}\text { Bekerja sesuai } \\
\text { urutan }\end{array}$ \\
\hline 2. & info-sejarah.php & $\begin{array}{l}\text { Bekerja sesuai } \\
\text { urutan }\end{array}$ \\
\hline 3. & lokasi.php & $\begin{array}{l}\text { Bekerja sesuai } \\
\text { urutan }\end{array}$ \\
\hline 4. & visi-misi.php & $\begin{array}{l}\text { Bekerja sesuai } \\
\text { urutan }\end{array}$ \\
\hline 5. & fasilitas.php & $\begin{array}{l}\text { Bekerja sesuai } \\
\text { urutan }\end{array}$ \\
\hline 6. & fakultas.php & $\begin{array}{l}\text { Bekerja sesuai } \\
\text { urutan }\end{array}$ \\
\hline 7. & input-login.html & $\begin{array}{l}\text { Bekerja sesuai } \\
\text { urutan }\end{array}$ \\
\hline 8. & struktur.php & $\begin{array}{l}\text { Bekerja sesuai } \\
\text { urutan }\end{array}$ \\
\hline 9. & sebaran-matkul.php & $\begin{array}{l}\text { Bekerja sesuai } \\
\text { urutan }\end{array}$ \\
\hline 10. & semester-ganjil.php & $\begin{array}{l}\text { Bekerja sesuai } \\
\text { urutan }\end{array}$ \\
\hline 11. & semester-genap.php & $\begin{array}{l}\text { Bekerja sesuai } \\
\text { urutan }\end{array}$ \\
\hline 12. & semester-padat.php & $\begin{array}{l}\text { Bekerja sesuai } \\
\text { urutan }\end{array}$ \\
\hline 13. & reguler.php & $\begin{array}{l}\text { Bekerja sesuai } \\
\text { urutan }\end{array}$ \\
\hline 14. & non-reguler.php & $\begin{array}{l}\text { Bekerja sesuai } \\
\text { urutan }\end{array}$ \\
\hline 15. & input-bantuan.html & $\begin{array}{l}\text { Bekerja sesuai } \\
\text { urutan }\end{array}$ \\
\hline
\end{tabular}

\section{KESIMPULAN}

Sistem pada aplikasi WAP ini dapat diakses melalui smartphone serta memberikan fasilitas dalam pencarian informasi akademik tentang info registrasi, display Kartu Rencana Studi (KRS), Kartu Hasil Studi (KHS), dan Rekap Hasil Studi (RHS). Jika adanya pengembangan nanti, tentu akan lebih lengkap lagi info yang akan ditampilkan disini.

Adanya keterkaitan antara aplikasi yang dibuat dengan program Kampus Merdeka dan menjadikan perguruan tinggi sebagai kampus digital, baik bagi pengelola maupun pengguna sistem informasi tersebut dalam pembuatan sistem informasi akademik menggunakan WAP, WML, PHP dan MySQL ini yang dapat dikembangkan kembali menjadi sebuah aplikasi android yang nantinya diunggah ke Play Store, sehingga aplikasinya akan lebih efektif dan efisien juga user friendly di mata para penggunanya.

Pengelolaan yang dilakukan terhadap sistem aplikasi ini adalah pendataan yang langsung online melalui media internet. Proses kerja program untuk dapat diakses melalui browser pada smartphone harus di-upload melalui server yang memfasilitasi aplikasi program WAP. Proses kerja aplikasi ditampilkan dengan cara memanggil alamat (domain) sistem informasi akademik yang telah terhubung dengan server. 


\section{REFERENSI}

Abdulghani, T., \& Solehudin, T. (2018). Sistem Informasi Pengelolaan Administratif Badan Usaha Milik Desa (BUMDes) Berbasis Client-Server Studi Kasus Di Desa Sindangasih Kecamatan Karang Tengah. Jurnal Ilmiah SANTIKA, 8(2), 241-254.

Ahmar, A. S. (2019). Panduan Sistem Informasi Akademik Sekolah Berbasis Web. Yayasan Ahmar Cendekia Indonesia.

Atikah, H. R., \& Sukadi. (2013). Sistem Informasi Simpan Pinjam Pada Koperasi Wanita Putri Harapan Desa Jatigunung Kecamatan Tulakan. IJNS - Indonesian Journal on Networking and Security, 2(4), 26-33. http://bit.ly/2AjzjRt

Dhanta dikutip dari Sanjaya. (2015). Aplikasi Berbasis Web. Aplikasi Berbasis Web.

Marhaeni. (2017). Rancang bangun aplikasi. Chemosphere, 7(1), Frieyadie, Kristiana, T. (2016). Rancang Bangun. http://dx.doi.org/10.1016/bs.ampbs.2017.04.001\%0Ahttp://dx.doi.org/10.1016/j.arabjc.2013.08.010\%0Aht tp://dx.doi.org/10.1016/j.chemosphere.2013.01.075\%0Ahttp://www.pnas.org/cgi/doi/10.1073/pnas.030855 5101\%0Ahttp://www.treemediation.com/technical/phytoremed

Prasetyo, B., Pattiasina, T. J., \& Soetarmono, A. N. (2015). Perancangan dan Pembuatan Sistem Informasi Gudang (Studi Kasus: PT. PLN (Persero) Area Surabaya Barat). Teknika, 4(1), 12-16. https://doi.org/10.34148/teknika.v4i1.30

Priyanto, D. (2013). Sistem Informasi Pemasaran Barang Dan Jasa Pada Batara Komputer Berbasis Wap. http://eprints.unisbank.ac.id/id/eprint/1483/

Pt, P., Listrik, P., Pln, N., \& Jme, K. P. B. (2011). KOTA PEKANBARU BERBASIS J2ME Periode Wisuda :

Sanjaya, D. (2015). Aplikasi Monitoring Kegiatan Mahasiswa Berbasis Android dan WEb. Jurnal Teknik Informatika, 5(MYsql), 479-484.

Setyawan, M. H. (2013). Sistem Informasi Akademik Berbasis Web SMA Negeri 1 Bandar Menggunakan PHP Dan MySQL. http://lib.unnes.ac.id/19116/1/4112309017.pdf

Triansah, A., Cahyadi, D., \& Astuti, I. F. (2016). Membangun Aplikasi Web Dan Mobile Android Untuk Media Pencarian Kost Menggunakan Phonegap Dan Google Maps API. Informatika Mulawarman : Jurnal Ilmiah Ilmu Komputer, 10(1), 58. https://doi.org/10.30872/jim.v10i1.21

Wijaya, S., Mulyanto, A., \& Mustakim, M. (2010). Sistem Informasi Penerimaan Mahasiswa Baru Berbasis Web Dan Wap. Seminar Nasional Vi Sdm Teknologi Nuklir, ISSN 1978-0176, 395-404. 